\title{
Erratum to: The Evaluation Process of Research Commercialization Proposals and its Links to University Technology Transfer (TT) Strategy: A Case Study
}

Odysseas Cartalos, Alexander N. Svoronos, and Elias G. Carayannis

\section{Erratum to:}

Chapter 14 in: N. Kalaitzandonakes et al. (eds.), From Agriscience to Agribusiness, Innovation, Technology, and Knowledge Management, https://doi.org/10.1007/978-3-319-67958-7_14

Chapter 14 titled "The Evaluation Process of Research Commercialization Proposals and its Links to University Technology Transfer (TT) Strategy: A Case Study", the equations in page no. 300 were corrected to read as:

$$
\begin{aligned}
& \text { BINRA : } \max _{x_{i}} \sum c_{i} x_{i} \\
& \text { LPRA : } \max _{x} \sum c_{i} x_{i}
\end{aligned}
$$

